\title{
HCHs and DDTs in Soils around Guanting Reservoir in Beijing, China: Spatial-Temporal Variation and Countermeasures
}

\author{
Tie-yu Wang, ${ }^{1}$ Bing Tan, ${ }^{1,2}$ and Yong-long Lu' ${ }^{1}$ \\ ${ }^{1}$ State Key Laboratory of Urban and Regional Ecology, Research Center for Eco-Environmental Sciences, \\ Chinese Academy of Sciences, Beijing 10085, China \\ ${ }^{2}$ College of Environmental Science and Engineering, Liaoning Technical University, Fuxin, Liaoning 123000, China
}

Correspondence should be addressed to Yong-long Lu, lurcees@gmail.com

Received 27 September 2012; Accepted 10 December 2012

Academic Editors: Y. Shimizu and F.-L. Xu

Copyright (C) 2012 Tie-yu Wang et al. This is an open access article distributed under the Creative Commons Attribution License, which permits unrestricted use, distribution, and reproduction in any medium, provided the original work is properly cited.

\begin{abstract}
The concentrations of hexachlorocyclohexanes (HCHs) and dichlorodiphenyltrichloroethanes (DDTs) in the topsoil samples around the Guanting Reservoir in Beijing were measured, and their spatial distribution and environmental risks were analyzed by GIS. The results showed that in 2003, 2007, and 2009, the HCHs concentrations were $0.66,0.85$, and $0.73 \mathrm{ng} / \mathrm{g}$, and the DDTs concentrations were 9.50, 7.80, and $6.46 \mathrm{ng} / \mathrm{g}$ in the studied area, respectively. In the topsoil, the HCHs concentrations did not change much while the DDTs concentrations declined steadily. Most of the current residues in soil come from the POPs used in the past years but some new input is also detected in certain regions. The level of HCHs and DDTs residues in the south reservoir is lower than that in the north reservoir. The middle region has the highest HCHs and DDTs concentrations, especially near the Beixinpu town. The high risk regions of pollution of HCHs and DDTs are mainly distributed in the vicinity of Beixinpu town as well. Based on the aforementioned results, a comprehensive countermeasure is proposed entailing decision making, local implementation, scientific support, and public participation with regard to the long-term control and management of POPs around the Guanting Reservoir.
\end{abstract}

\section{Introduction}

Hexachlorocyclohexanes (HCHs) and dichlorodiphenyltrichloroethanes (DDTs) have been listed as the main pesticidal persistent organic pollutants (POPs) by the United Nations Environment Program (UNEP) in the Stockholm Convention. They have been used in China on a large scale for a long time and the pesticides used in China during 1960-1980 were mainly organochlorine pesticides (OCPs). The consumption of OCPs such as DDTs and HCHs were 192,000 tons in 1970 , accounting for $80.1 \%$ of the total domestic pesticide production [1, 2]. From 1972 to 1974, the agricultural consumption of HCHs and DDTs amounted to 607.8 tons and 150.8 tons, respectively, in the Beijing municipality [3]. In the early 1980s, the application of pesticidal POPs in the orchards became restricted and after 1983 the comprehensive restrictions on their production and use took effect [4]. However, the environmental problems caused by their toxicity, nonbiodegradability, bioaccumulation, and so forth still seriously threaten human health and environmental well-being $[5,6]$. Soil is a reservoir for the OCPs and has gradually changed from a major sink to an important emission source of OCPs to food and drinking water over time. Significant proportions of between $20 \%$ and $70 \%$ of a pesticide or its degradation products can remain in soil following application [7].

The Guanting Reservoir is located on the Yongding River at $100 \mathrm{~km}$ northwest of Beijing. It has a water capacity of 4.2 billion $\mathrm{m}^{3}$ and includes $46,000 \mathrm{~km}^{2}$ water shed areas. It was previously one of the most important water sources for Beijing until 1997 when its water was polluted. To enable the effective comprehensive management of the Guanting Reservoir and restore its function to supply drinking water, many studies focusing on pesticidal POPs have been carried out around the reservoir [8-10]. However, the potential nonpoint source pollution of POPs 


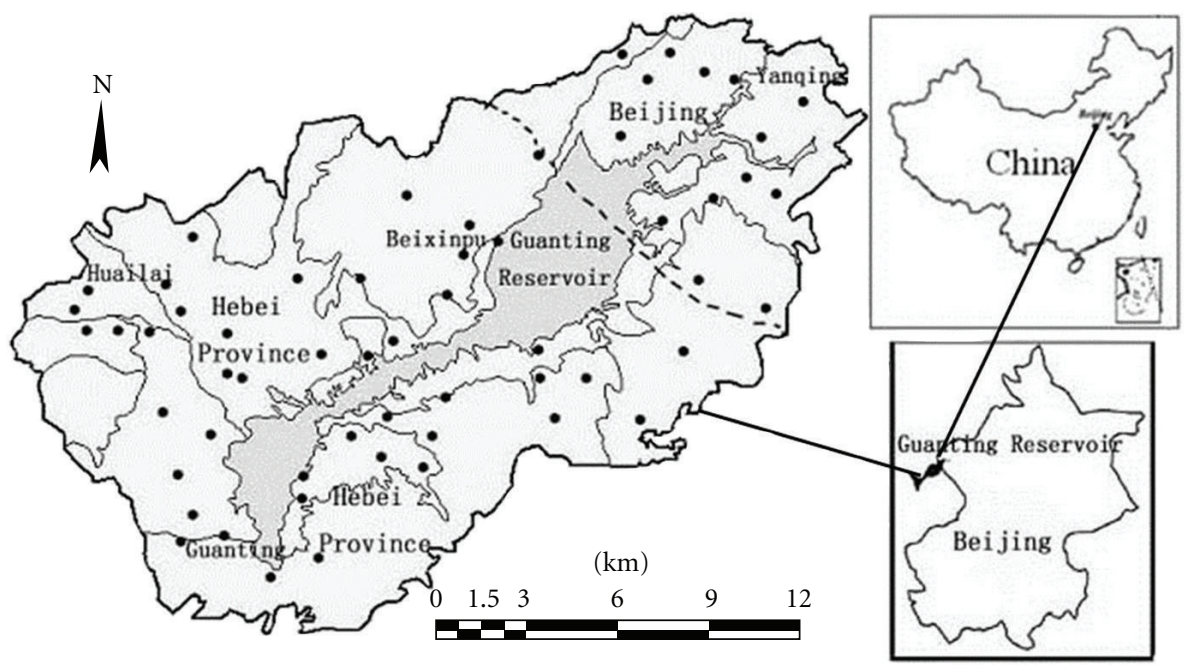

FIGURE 1: Locations of sampling sites around the Guanting Reservoir.

from farmlands around the reservoir was rarely reported. Since 2003, we embarked on the continuous integrated and systematic studies by fixing points in the soils around the reservoir [11-16]. Through multiyear monitoring and using GIS technology, we evaluated the pollution situation and risk pattern of pesticidal POPs in the soils around the water shed. The analyses presented in this paper will facilitate better understanding of the residue characteristics and tendency effects of OCPs in soils under various conditions around water sheds. Consequently, we proposed specific countermeasures to remedy regional ecological environment and provided the scientific basis for the comprehensive treatment of the reservoir and a technical framework for water source protection and management projects in the future.

\section{Materials and Methods}

2.1. Sample Collection. This study focused on a $920 \mathrm{~km}^{2}$ water shed within $2-10 \mathrm{~km}$ around the Guanting Reservoir $\left(115.43^{\circ} \mathrm{E}-115.97^{\circ} \mathrm{E}, 40.19^{\circ} \mathrm{N}-40.50^{\circ} \mathrm{N}\right)$. The soil types are mainly brown soil, cinnamon soil, and chestnut soil. Land use in the area includes orchards, corn fields, vegetable fields, and forest shrubs. The 58 topsoil samples were collected and analyzed in 2003, 2007, and 2009, respectively. Each sample consisted of a mixture of soil collected from five subsites at a depth of $0-20 \mathrm{~cm}$, each of which covering a radius of $5 \mathrm{~m}$ in a cross-pattern. Throughout the survey, a global positioning system (GPS) was used to locate the sampling sites to ensure the valid space registration of the sampling sites in different years. The locations of the sampling sites are shown in Figure 1.

2.2. Sample Treatment. All soil samples were air dried at room temperature, then ground with sticks, and passed through a $2 \mathrm{~mm}$ nylon mesh to remove grit, plant, and animal residues from the soil samples, and finally stored in polypropylene (PP) plastic bags until analysis. The analysis method follows the previous report [15] and is summarized as follows. Each soil sample (10 g) was weighed accurately and decanted into a $150 \mathrm{~mL}$ Erlenmeyer flask, and an appropriate amount of high purity active copper powder and anhydrous sodium sulfate were added to the samples to remove sulfur and water. The sample was then extracted with $100 \mathrm{~mL} 7: 3(\mathrm{v} / \mathrm{v}) n$-hexane/dichloromethane in an ultrasonic bath for several times. The extract was transferred into a glass centrifugal tube and centrifuged at $3000 \mathrm{rpm}$ and then decanted into a $250 \mathrm{~mL}$ separating funnel where concentrated sulfuric acid was added to purify the extract. After discarding the sulfonated layer, the purified extract was washed at least twice with $10 \%$ sodium chloride solution until the $\mathrm{pH}$ value of the solution was close to 7 and was then concentrated under reduced pressure to about $2 \mathrm{~mL}$ and decanted into a $5 \mathrm{~mL}$ graduated test tube. The obtained residue was reduced to a final volume of $0.5 \mathrm{~mL}$ under a gentle stream of ultrahigh purity nitrogen (99.99\%) for GC analysis.

2.3. Sample Analysis. The final extract of pesticidal POPs was analyzed on an HP 6890 gas chromatograph equipped with a ${ }^{63} \mathrm{Ni}$ electron capture detector ( $\mu$ ECD) using an HP1 silica capillary column $(30 \mathrm{~m} \times 0.32 \mathrm{~mm}$ i.d. $\times 32 \mu \mathrm{m})$. The injector and detector temperatures were 220 and $300^{\circ} \mathrm{C}$, respectively. The oven temperature was started from $150^{\circ} \mathrm{C}$ and increased at $5^{\circ} \mathrm{C} / \mathrm{min}$, then maintained at $200^{\circ} \mathrm{C}$ for $2 \mathrm{~min}$, and then increased again at $8^{\circ} \mathrm{C} / \mathrm{min}$ and finally maintained at $270^{\circ} \mathrm{C}$ for $5 \mathrm{~min}$. The injection was splitless and the injection volume was $1 \mu \mathrm{L}$. Ultrahigh purity nitrogen was used as the carrier gas. The Stigma pressure of nitrogen was $60 \mathrm{kPa}$, and $60 \mathrm{~mL} / \mathrm{min}$ nitrogen was used as the makeup gas. The pesticidal POPs were identified by retention time and quantified using external standard.

A mixture of standard solution containing $\alpha-\mathrm{HCH}$, $\beta-\mathrm{HCH}, \quad \gamma-\mathrm{HCH}, \delta-\mathrm{HCH}$ isomers, and $\mathrm{pp}^{\prime}-\mathrm{DDE}, \mathrm{pp}^{\prime}-$ DDD, op'-DDT, $\mathrm{pp}^{\prime}$-DDT were obtained from the National Research Center for Certified Reference Materials of China. 
TABle 1: Concentrations (ng/g dw) of OCPs in soil samples in 2003, 2007, and 2009.

\begin{tabular}{|c|c|c|c|c|}
\hline \multirow{2}{*}{ Variables } & & \multicolumn{3}{|c|}{ Mean \pm SD $(\min -\max )$} \\
\hline & & 2003 & 2007 & 2009 \\
\hline \multirow{5}{*}{ HCHs group } & $\alpha-\mathrm{HCH}$ & $0.06 \pm 0.14(\mathrm{nd}-0.78)$ & $0.02 \pm 0.05(\mathrm{nd}-0.27)$ & $0.03 \pm 0.08(\mathrm{nd}-0.48)$ \\
\hline & $\beta-\mathrm{HCH}$ & $0.36 \pm 0.68(\mathrm{nd}-2.74)$ & $0.59 \pm 0.94(\mathrm{nd}-4.58)$ & $0.69 \pm 1.83(\mathrm{nd}-14.34)$ \\
\hline & $\gamma-\mathrm{HCH}$ & $0.06 \pm 0.20(\mathrm{nd}-1.41)$ & $0.16 \pm 0.19(\mathrm{nd}-1.01)$ & $0.01 \pm 0.03(\mathrm{nd}-0.15)$ \\
\hline & $\delta-\mathrm{HCH}$ & $0.19 \pm 0.61(\mathrm{nd}-3.55)$ & $0.07 \pm 0.22(\mathrm{nd}-1.53)$ & $0.02 \pm 0.06(\mathrm{nd}-0.30)$ \\
\hline & $\sum \mathrm{HCH}$ & $0.66 \pm 1.34(\mathrm{nd}-7.33)$ & $0.85 \pm 1.18(\mathrm{nd}-5.56)$ & $0.73 \pm 1.92($ nd -14.97$)$ \\
\hline \multirow{5}{*}{ DDTs group } & $p, p^{\prime}-D D E$ & $4.71 \pm 9.42(\mathrm{nd}-52.20)$ & $3.88 \pm 10.69(\mathrm{nd}-78.07)$ & $5.07 \pm 11.59(\mathrm{nd}-55.96)$ \\
\hline & $\mathrm{p}, \mathrm{p}^{\prime}-\mathrm{DDD}$ & $0.24 \pm 0.61(\mathrm{nd}-3.37)$ & $0.11 \pm 0.33(\mathrm{nd}-1.76)$ & $0.73 \pm 1.70(\mathrm{nd}-9.71)$ \\
\hline & $\mathrm{o}, \mathrm{p}^{\prime}-\mathrm{DDT}$ & $0.84 \pm 2.30($ nd -11.71$)$ & $0.75 \pm 1.81(\mathrm{nd}-9.04)$ & $0.08 \pm 0.47(\mathrm{nd}-3.55)$ \\
\hline & $\mathrm{p}, \mathrm{p}^{\prime}-\mathrm{DDT}$ & $3.67 \pm 7.75(\mathrm{nd}-33.08)$ & $2.98 \pm 7.38($ nd -50.73$)$ & $0.58 \pm 1.30(\mathrm{nd}-7.34)$ \\
\hline & $\sum \mathrm{DDT}$ & $9.46 \pm 17.76(\mathrm{nd}-76.01)$ & $7.84 \pm 17.68(\mathrm{nd}-116.74)$ & $6.46 \pm 13.28(\mathrm{nd}-64.91)$ \\
\hline Reference & & {$[16]$} & {$[19]$} & Present study \\
\hline
\end{tabular}

*nd: the value less than LOD (limits of detection) was set to nd.

TABle 2: Composition of HCH and DDT in soil samples in 2003, 2007, and 2009.

\begin{tabular}{|c|c|c|c|c|c|}
\hline Ratio & Year & Average & Minimum & Maximum & $\begin{array}{c}\text { Percentage of sites } \\
\text { with a ratio less than } 1\end{array}$ \\
\hline \multirow{3}{*}{$\alpha-\mathrm{HCH} / \gamma-\mathrm{HCH}$} & 2003 & 1.35 & 0.25 & 3.35 & $8.9 \%$ \\
\hline & 2007 & 0.42 & 0.12 & 0.73 & $15.0 \%$ \\
\hline & 2009 & 2.76 & 2.25 & 3.26 & 0 \\
\hline \multirow{3}{*}{$(\mathrm{DDE}+\mathrm{DDD}) / \mathrm{p}, \mathrm{p}^{\prime}-\mathrm{DDT}$} & 2003 & 2.52 & 0.24 & 25.2 & $23.2 \%$ \\
\hline & 2007 & 1.25 & 0.09 & 4.22 & $41.7 \%$ \\
\hline & 2009 & 7.07 & 0.24 & 40.1 & $8.2 \%$ \\
\hline
\end{tabular}

For quality assurance and control, procedural blanks and matrixes spiked with the standard solution were analyzed. None of the target compounds were detected in the procedural blanks. All solvents used were distilled in glass (PR grade) and were checked for interferences or contamination prior to use. The amount of substance in the extracts was quantified using the internal standard (2,4,5,6-tetrachloro$m$-xylene). The recovery of the four $\mathrm{HCH}$ isomers $(\alpha-$ $\mathrm{HCH}, \beta-\mathrm{HCH}, \gamma-\mathrm{HCH}, \delta-\mathrm{HCH})$ and four DDT homologues (pp'-DDE, $\mathrm{pp}^{\prime}$-DDD, op' ${ }^{\prime}$ DDT, $\mathrm{pp}^{\prime}$-DDT) were $73.3 \%$, $90.3 \%, 75.8 \%, 85.6 \%$ and $80.0 \%, 93.8 \%, 95.4 \%$, and $96.2 \%$, respectively. The extraction efficiency, as indicated by the recovery of the surrogate standards (TCMX), was $75 \% \pm 10 \%$. The detection limit was set to three times the signal-to-noise ratio $(S / N)$. The detection limit ranged from 0.06 to $0.15 \mathrm{ng} / \mathrm{g}$ for the $\mathrm{HCH}$ isomers and from 0.07 to $0.19 \mathrm{ng} / \mathrm{g}$ for the DDT homologues. Reagent blanks were also analyzed simultaneously with the experimental samples.

2.4. Data Processing. The software used for the mapping and spatial analysis was ArcGis 10.0(ESRI, US). An interpolation method called Ordinary Kriging was adopted for the interpolation of geographical data. SPSS 11.5 for Windows was employed for statistical analysis. Excel (version 2007, Microsoft) was also used for preliminary data analysis and histogram graphing.

\section{Results and Discussion}

3.1. Temporal Variation of Residual Pesticidal POPs in Soils. Table 1 shows that, from 2003 to 2009, the HCHs concentrations in topsoil did not change much, while the DDTs concentrations declined steadily. Specifically, the $\beta-\mathrm{HCH}$ isomers were enriched in the soil, whereas the content of $\alpha-\mathrm{HCH}$ isomers declined. The concentrations of $\gamma-\mathrm{HCH}$ isomer $(0.01 \mathrm{ng} / \mathrm{g} \mathrm{dw})$ and $\delta-\mathrm{HCH}$ isomer $(0.02 \mathrm{ng} / \mathrm{g} \mathrm{dw})$ in 2009 are also less than those in $2003(0.06 \mathrm{ng} / \mathrm{g} \mathrm{dw}$ and $0.19 \mathrm{ng} / \mathrm{g} \mathrm{dw})$ or $2007(0.16 \mathrm{ng} / \mathrm{g} \mathrm{dw}$ and $0.07 \mathrm{ng} / \mathrm{g} \mathrm{dw})$. The ratio of $\alpha-\mathrm{HCH}$ to $\gamma-\mathrm{HCH}$ is often considered the characteristic index to determine the source of the HCHs. The value of ratio between 4 and 7 in samples implies that there may be new source of HCHs; a ratio close to 1 may indicate new industrial input of lindane and a ratio greater than 7 may suggest long distance atmospheric transport of HCHs [17]. As Table 2 shows 8.9\% of the samples in 2003 and $15 \%$ of the samples in 2007 had $\alpha-\mathrm{HCH} / \gamma-\mathrm{HCH}$ ratio less than 1 . The result indicates that the main $\mathrm{HCH}$ input is from lindane and there may have been new industrial pollution source after restricting $\mathrm{HCH}$ usage. Previous studies by Wang et al. (2003), Sun et al. (2005), and Xue et al. (2005) on the Guanting Reservoir also showed that the HCHs in water may be due to the input of lindane or industrial $\mathrm{HCH}$ from the upstream or surrounding regions $[3,8,9]$. However, according to the environmental monitoring in 2009, there was no new industrial lindane pollution source 


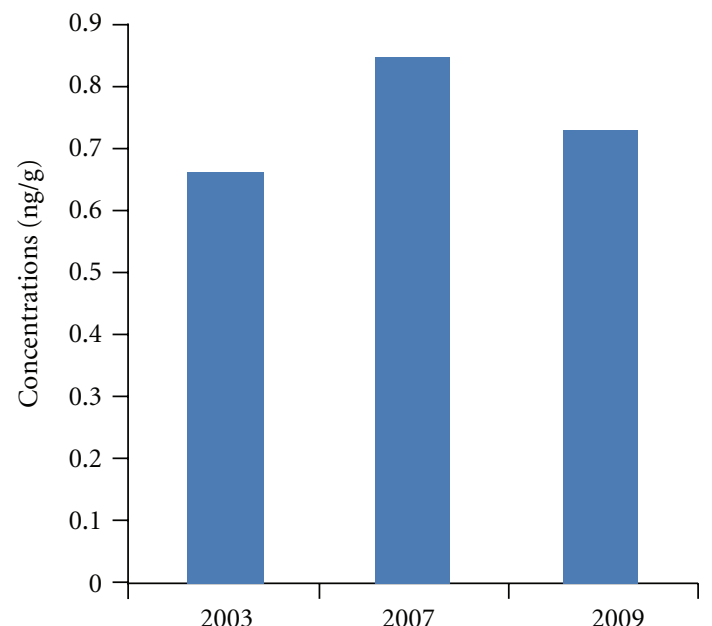

$\sum \mathrm{HCH}$

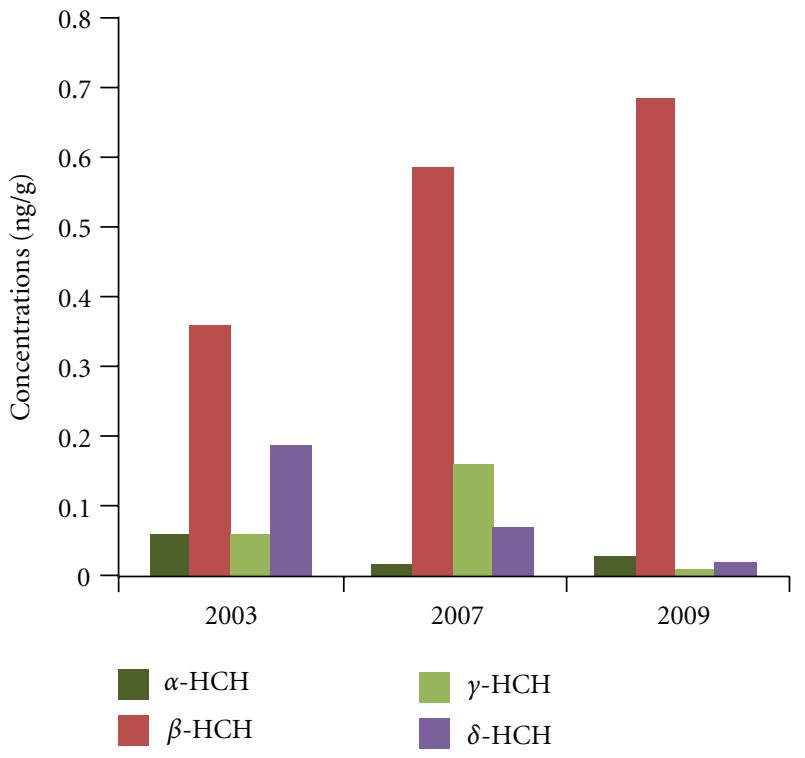

(b)

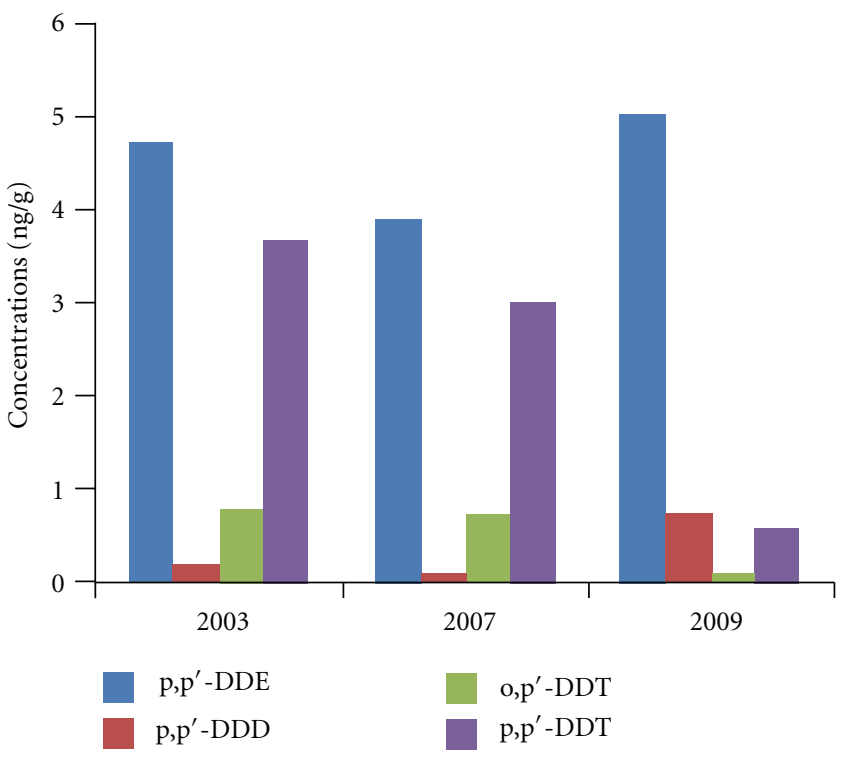

(d)

(c)

Figure 2: Temporal trends of HCHs and DDTs in soils from 2003 to 2009.

near the Guanting region, because $\alpha-\mathrm{HCH} / \gamma-\mathrm{HCH}$ ratio of each sample was much higher than 1 .

By comparing with previously reported results $[16,18$, 19], it can be seen that DDTs have always been the main components of pesticidal POPs in the Guanting Reservoir area, that is, $93.2 \%$ in $2003,90.2 \%$ in 2007 , and $90.6 \%$ in 2009, respectively. Figure 2 shows that the concentration of $\mathrm{pp}^{\prime}$-DDE in soil is the greatest in 2009. Besides, the concentration of $\mathrm{pp}^{\prime}$-DDT in soil gradually decreased from

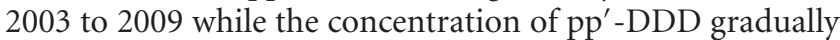
increased. These results indicate that $\mathrm{pp}^{\prime}$-DDT has gradually degraded to $\mathrm{pp}^{\prime}$-DDD and $\mathrm{pp}^{\prime}$-DDE mainly through aerobic degradation. Although DDT can degrade relatively more easily, its degradation products DDE and DDD are more stable and more difficult to degrade. The ratio of (DDE + DDD) to $\mathrm{pp}^{\prime}$-DDT is usually considered a characteristic index to determine the source of DDT in the environment [20]. Table 2 shows that $23.2 \%$ of the samples in 2003 and $41.7 \%$ of the samples in 2007 had a (DDE + DDD) to $\mathrm{pp}^{\prime}-$ DDT ratio of less than 1 . This indicates that DDTs such as dicofol or other pesticides containing DDTs as by-product were still used during that time in this region. Dicofol products have a high DDT content varying from 3.54\% to $10.8 \%$. Since the $1960 \mathrm{~s}$, in each year 2000 tons of dicofol products were put into use. As a result, dicofol may be the new source of DDT pollution [21]. Table 2 also shows that only about $8.2 \%$ of the samples had a (DDE + DDD) to $\mathrm{pp}^{\prime}$ DDT ratio less than 1 in 2009. Hence, this new DDT source is 
basically under control and the environmental exposure was mainly due to the historical use of dicofol.

Concentrations of HCHs and DDTs in soils were compared with the soil quality reference values recommended in China and The Netherlands [22]. According to the guidelines of the Chinese environmental quality standards for soil (GB 15618-1995), the limits for $\mathrm{HCH}$ and DDT in the soils are both 50,500 , and $1,000 \mathrm{ng} / \mathrm{g} \mathrm{dw}$, corresponding to Class I, II, and III, respectively. In 2003 and 2007, concentrations of $\mathrm{HCHs}$ in all soil samples were below the limit of Class I (50 ng/g dw) and Dutch target value (10 ng/g dw). While in 2009, HCHs concentrations were also within the limit of Class I but in several sites exceeded the Dutch target value. With regard to DDTs, mean concentrations of DDTs were within the criteria for Class I and Dutch target value in different years. In general, even concentrations of $\mathrm{HCHs}$ and DDTs were both less than the Chinese criteria Class I, which is set to ensure the safety of agricultural products and to prevent foods contamination from $\mathrm{HCHs}$ and DDTs; they still could have negative impacts on local atmosphere and aquatic ecosystem in the long term because of their nonbiodegradability and bioaccumulation.

3.2. Spatial Variation of Pesticidal POPs in Soils. The spatial evolution patterns of HCHs and DDTs in soils were analyzed using the Geostatistical Analyst in the GS extension module of ArcGis with ordinary Kriging interpolation. The results in Figure 3 show that, in 2003, 2007, and 2009, the residual pesticidal POPs vary significantly in different areas around the Guanting Reservoir. The HCHs and DDTs are mainly concentrated in the Beixinpu town and the Huailai county, and their concentrations decreased from north to south. Generally speaking, the concentrations of HCHs and DDTs in the south reservoir were lower than those in north reservoir both before and after the pesticide restriction took effect. This is because (1) agriculture is less developed in the south reservoir and (2) the sandy and weathering soils in the south reservoir speed up the degradation and evaporation of POPs. The Beixinpu town is located in the middle of the north reservoir area. It connects the mountains in the north with the water in the south and has a decreasing geomorphological gradient from north to south. The Beixinpu town has large areas of shrub forests and orchards and used large amounts of $\mathrm{HCH}$ and DDT in the 1970s for forestry pest control. Currently lots of pesticides that may contain POPs isomers or degradation products (such as dicofol) are still consumed in the orchards in this area. This may explain why the residual amounts of $\mathrm{HCH}$ and DDT were high in the Beixinpu town compared with other areas.

The Huailai county (in Hebei province) located in the central and western Guanting Reservoir area was found to have high $\mathrm{HCH}$ exposures, and the Beixinpu town was found to have the highest risk. The concentration of $\mathrm{HCHs}$ in the Beixinpu town was relatively high in 2003, but, after six years of degradation, it decreased to a normal level not significantly different with its surrounding. Previous studies have also shown that the concentrations of heavy metals in the Beixinpu town are also very high $[13,23]$. The Yanghe river and the Sanggan river are the major pollution sources of the Guanting Reservoir. Although the insecticide factories, chemical plants, and printing and dyeing mills located in Zhangjiakou and Xuanhua at the upstream of the Yanghe river have been partially shut down, serious pollution has already occurred. Furthermore, because of the agricultural irrigation in those water sheds, the pollutants including pesticidal POPs were spread to the surrounding soils, leading to high environmental risks. In 2003, the soil DDTs were mainly concentrated in three regions: the western reservoir (near Huailai county), the central reservoir (Beixinpu town), and the eastern reservoir (Yanqing county). The DDT concentrations in the northern regions were higher than those in the southern regions (Figure 3 ). In particular, the large historical use of DDTs in the Beixinpu area and the new input of pesticidal POPs resulted in much higher DDTs residues in those regions compared with their surroundings, which shows a patchy distribution of high pollution risks. Until 2007, the high pollution risk areas were still concentrated in these three regions, but the acreage of the high pollution risk areas decreased in the central Beixinpu town and Yanqing county. In 2007 the soil DDTs showed no obvious regional aggregation and its overall level declined substantially. Until 2009, the concentrations of DDTs in the high pollution risk areas in the northern Guanting Reservoir further declined from a maximum of $116.74 \mathrm{ng} / \mathrm{g} \mathrm{dw}$ to $64.91 \mathrm{ng} / \mathrm{g} \mathrm{dw}$ (Table 1). According to the Chinese Environmental Quality Standard for soils, the concentrations of $\mathrm{HCH}$ in this area were far below the first grade (class I $=50 \mathrm{ng} / \mathrm{g} \mathrm{dw}$ ). Only two sampling sites had DDTs concentrations slightly exceeding the first grade in $2009(64.91 \mathrm{ng} / \mathrm{g} \mathrm{dw}$ and $59.05 \mathrm{ng} / \mathrm{g} \mathrm{dw}$, resp.), which accounted for only $3.3 \%$ of all samples. Overall, after years of pesticide restriction and natural degradation, the pesticidal POPs residues in the soils of studied areas decreased steadily. However, new pollution sources such as lindane and dicofol may exist in some sampling sites and should receive more attention.

\subsection{Management and Control of Pesticidal POPs around the Guanting Reservoir}

3.3.1. Integrated Management Framework for Regional POPs Control. By analyzing the temporal and spatial distribution pattern of pesticidal POPs around the Guanting Reservoir based on previous and present studies, a framework of ecoenvironmental countermeasures is put forward for regional POPs control (Figure 4) [24-26]. The establishment and implementation of regional policies should be based on scientific investigation, led by policy analysis, and completed under the common goal of governmental decision-making, local implementation, scientific support, and public participation. This framework includes 18 specific regional ecoenvironmental countermeasures (1) to improve the policy and the regulation system related to pesticidal POPs; (2) improve or develop pesticidal standards and criteria in different media; (3) publicize the environmental hazards of POPs through the local government; (4) strengthen public 

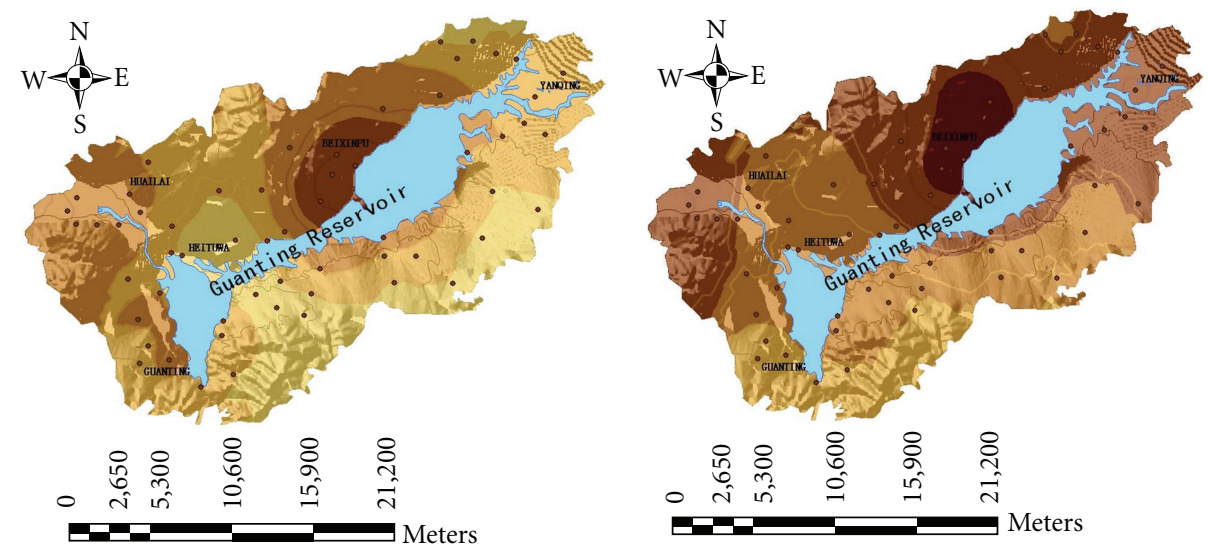

2003 samples HCHs

$0-0.0772$
$0.0772-0.2477$
$0.2477-0.6238$

$$
\begin{aligned}
& 0.6238-1.4538 \\
& 1.4538-3.2853 \\
& 3.2853-7.327
\end{aligned}
$$

(a)

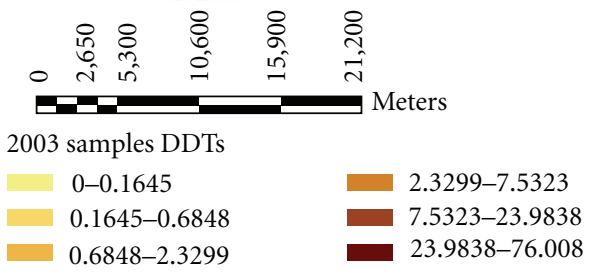

(b)
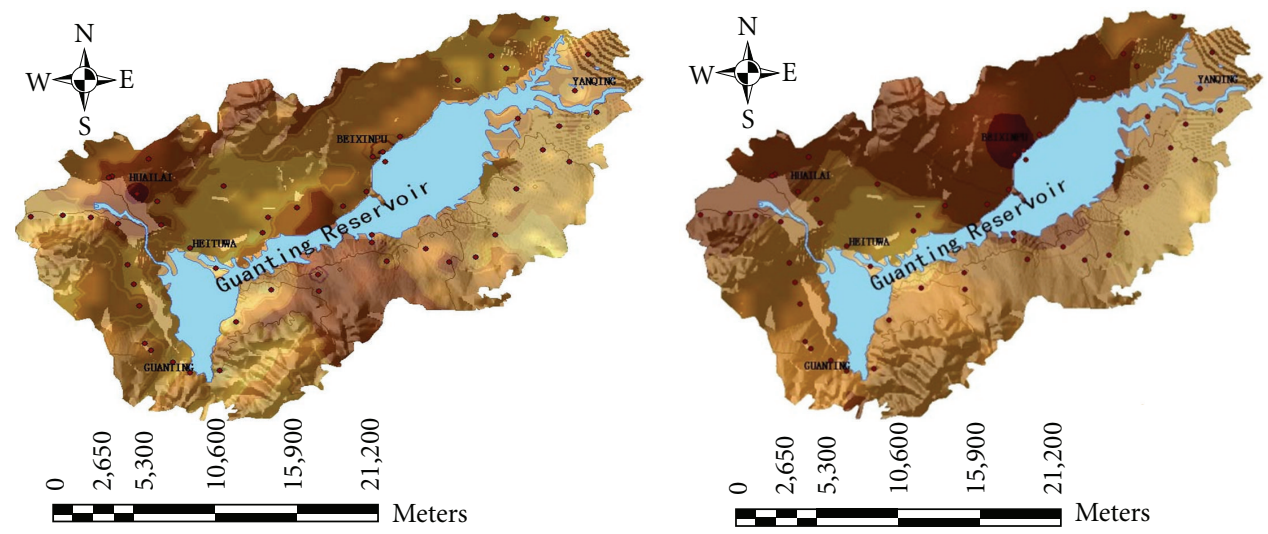

2007 samples HCHs

$\begin{array}{ll}0-0.0681 & 0.5219-1.1791 \\ 0.0681-0.2132 & 1.1791-2.5782 \\ 0.2132-0.5219 & 2.5782-5.5564\end{array}$

(c)
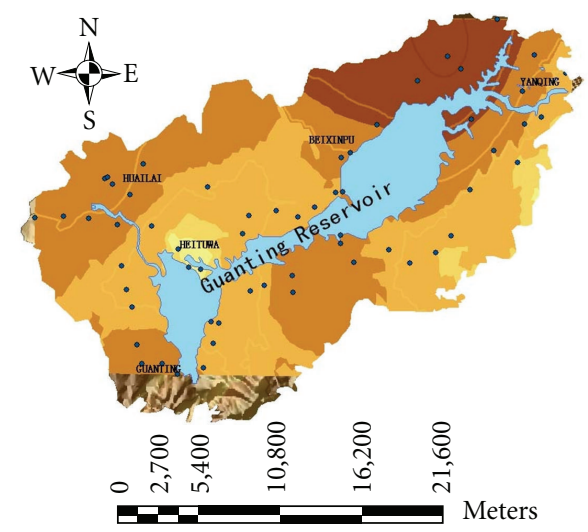

2009 samples $\mathrm{HCHs}$

$0-0.2202$
$0.2202-0.2806$
$0.2806-0.5008$

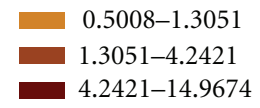

(e)
2007 samples DDTs

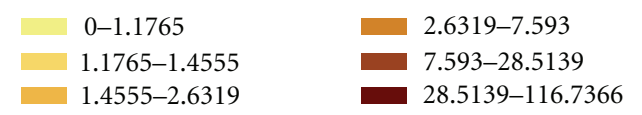

(d)

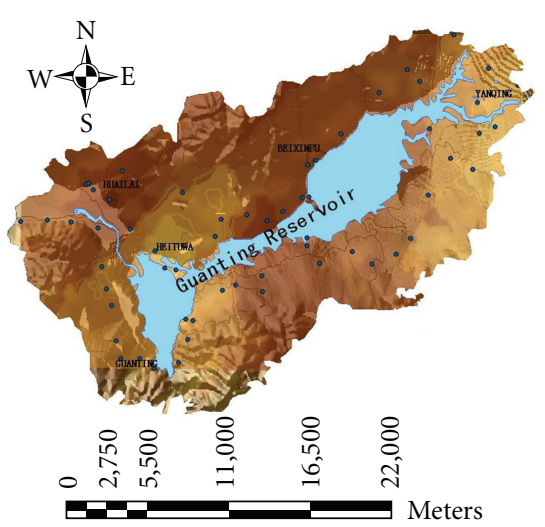

2009 samples DDTs

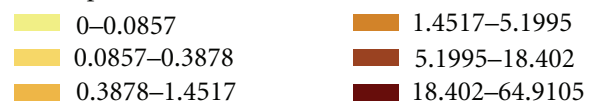

(f)

FIGURE 3: Spatial-temporal trend of HCHs and DDTs in soils around the Guanting Reservoir. 


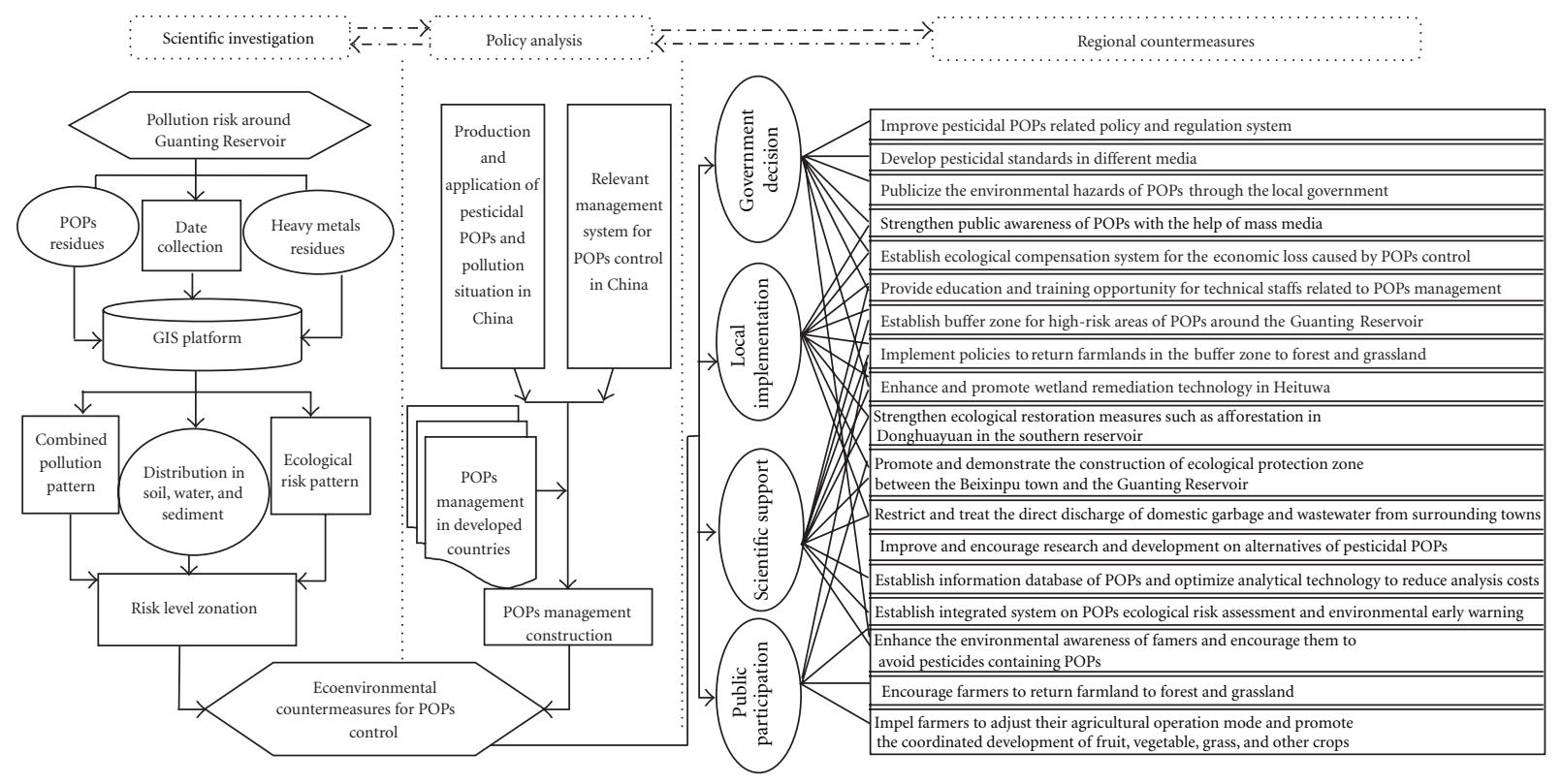

FIgURE 4: Framework of regional POPs management in the Guanting area.

awareness of POPs through mass media; (5) establish the ecological compensation system for the economic loss due to POPs control; (6) provide education and training opportunity for the technical staffs of POPs management; (7) establish buffer zones around the Guanting reservoir for high-risk areas of POPs; (8) implement policies to return farmlands in the buffer zone to forest and grassland; (9) enhance the diffuse wetland remediation technology in Heituwa; (10) strengthen the ecological restoration measures such as afforestation in Donghuayuan in the southern reservoir; (11) promote and demonstrate the construction of ecological protection zone between the Beixinpu town and the reservoir; (12) restrict and control the direct discharge of domestic garbage and wastewater from surrounding towns; (13) improve and encourage R\&D on alternatives of pesticidal POPs; (14) establish the POPs information database and optimize the analytical technology for POPs; (15) establish integrated system on ecological risk assessment and environmental earlywarning of POPs; (16) enhance the environmental awareness of farmers and encourage them to avoid pesticides containing POPs; (17) encourage farmers to return farmland to forest and grassland; (18) impel farmers to adjust agricultural operation mode and promote the coordinated development of fruit, vegetable, grass, and other crops.

3.3.2. Ecoengineering Measures to Control POPs in Specific Areas. With the use of overlay analysis in GIS, the ecological risk near the Guanting Reservoir was classified into five grades based on its spatial distribution pattern. Meanwhile, specific ecological countermeasures for typical regions are proposed in Figure 5.

Sewage Purification by Artificial Wetland between Yanghe River and Heituwa. The chemical plants located at the upstream of the Yanghe river in Zhangjiakou once caused serious pollution in the Guanting Reservoir. The Yanghe river lies between the reservoir in the Yongding river and the Huailai county and still has high concentrations of $\mathrm{HCH}$ and DDTs. Therefore, to protect the water quality of the Guanting Reservoir, the environmental management and ecological restoration in this region must be strengthened. The construction of the Heituwa artificial wetland is a crucial part of the water quality improvement project of the Guanting Reservoir, and it is also the first ecological barrier to the polluted water from Yongding river flowing into the Guanting Reservoir. The construction of 84 hectares of ecological purification ponds and 7.4 hectares of wetland has been planned in the Heituwa artificial wetland. A floatingleaved plant zone of 2.52 hectares and an emergent vegetation zone of 6.84 hectares will be artificially planted, leaving the remaining areas to be covered by natural reproduction.

For ecological purification, the artificial wetland construction could also be carried out in some other areas based on the experience of the Heituwa artificial wetland. The construction of another artificial wetland at the upstream of the Guishui river near the Yanqing county is recommended to effectively prevent the pollution from industrial activities and domestic sewage discharge. The consolidated utilization of forests, arbor, shrubs, and grass can purify surface runoff, reduce reservoir sedimentation, alleviate nonpoint source pollution, recover the ecological functions, and improve the landscape around reservoir.

Forest and Grass Protection Buffer Zone between North Reservoir and Beixinpu. The large areas of orchards in the Beixinpu town are a substantial source of pesticides and fertilizers. It was reported that the Beixinpu town was once the most heavily polluted region around the Guanting Reservoir, in particular suffering from combined 

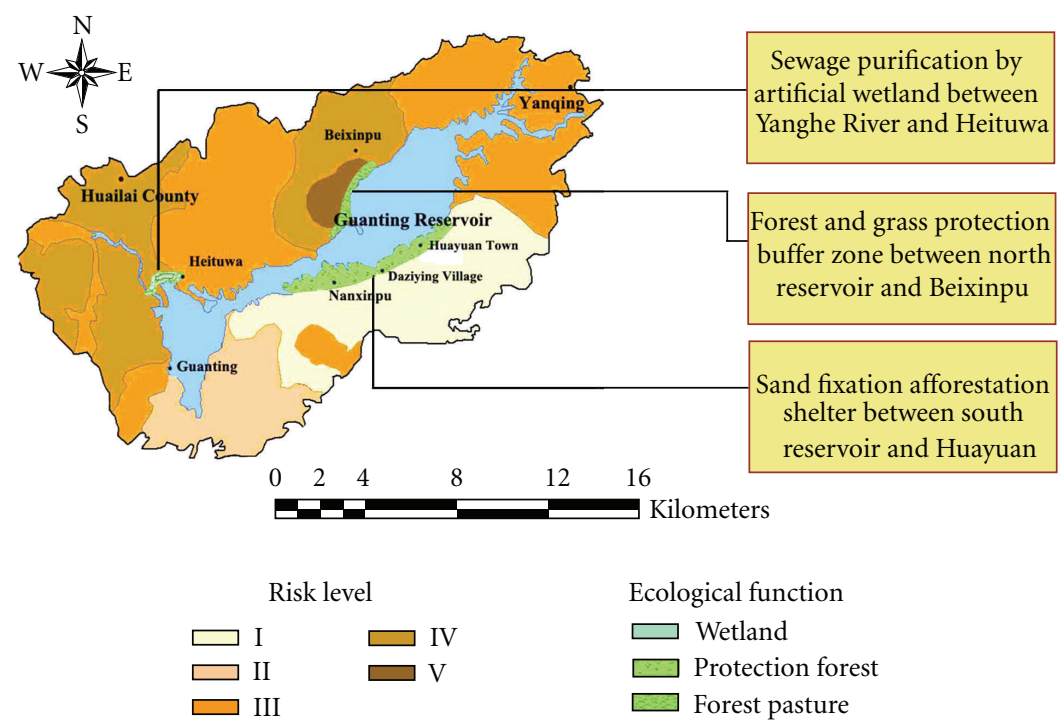

FIGURE 5: Ecological engineering projects around the Guanting Reservoir.

pollutions of DDTs and HCHs [23]. A buffer zone is strongly recommended in the sensitive areas around the reservoir between the Beixinpu town and the Huailai county. Through returning farmland to forest and grassland, the construction of a buffer strip approximately $7 \mathrm{~km}$ long and $200 \mathrm{~m}$ wide is recommended between the orchards and the water body. This buffer system can successively filtrate the pollutants through farm (orchard), forestry, shrub (grass), and water, which not only blocks the input of pesticidal POPs from the Beixinpu town due to runoffs, infiltration, and soil erosion but also fixes those POPs coming from short-distance atmospheric migration or pesticides-cemented dusts.

Sand Fixation Afforestation Shelter between South Reservoir and Huayuan. The south reservoir has poor sandy soils and is not suitable for agriculture, forestry or grass cultivation. The construction of a shelter forest approximately $14 \mathrm{~km}$ long and $500 \mathrm{~m}$ wide is proposed, using shrubs with barren resistance and low water consumption.

Meanwhile, the corresponding economic compensation system should be established for the farmers affected by the ecological protection and agriculture limitation policies. In order to transform the POPs management from passive control to active prevention, it is necessary to strengthen the public awareness of the environmental and health hazards of POPs, promote relevant policies and regulations, and foster public understanding and coordination.

\section{Conclusions}

This study measured the spatial and temporal variability of $\mathrm{HCH}$ and DDT concentrations in the soils around the Guanting Reservoir of Beijing. From 2003 to 2009, the DDT concentrations decreased significantly while the $\mathrm{HCH}$ concentrations did not change much. The agricultural pesticide application in this region at earlier times was the main source of $\mathrm{HCH}$ and DDT. In the past several decades, China has produced and used large quantities of pesticidal POPs for agriculture purposes and for preventing infectious diseases. Therefore, monitoring databases, especially longterm systematic survey, should be expanded to fully understand this problem.

On the basis of previous and present studies on pesticidal POPs around this water shed, an integrated regional POPs control framework was established. The framework involves scientific investigation, policy analysis, and regional countermeasures, and 18 specific countermeasures are proposed that cover government decision making, local implementation, scientific and technology support, as well as public participation.

\section{Acknowledgments}

This study was supported by the National Natural Science Foundation of China under Grant no. 41171394 and 41071355, and the International Scientific Cooperation Program with Grant no. 2012DFA91150. Finally, the authors thank the editors and reviewers for their valuable comments and suggestions.

\section{References}

[1] D. Wei, T. Kameya, and K. Urano, "Environmental management of pesticidal POPs in China: past, present and future," Environment International, vol. 33, no. 7, pp. 894-902, 2007.

[2] W. Tieyu, L. Yonglong, Z. Hong, and S. Yajuan, "Contamination of persistent organic pollutants (POPs) and relevant management in China," Environment International, vol. 31, no. 6, pp. 813-821, 2005.

[3] X. T. Wang, S. G. Chu, and X. B. Xu, "Organochlorine pesticide residues in water from Guanting reservoir and Yongding River, China," Bulletin of Environmental Contamination and Toxicology, vol. 70, no. 2, pp. 351-358, 2003. 
[4] State Environmental Protection Administration, "China's pesticide pollution and its being problems and suggestions," Environmental Protection, vol. 6, pp. 23-24, 2001.

[5] F. Wania and D. Mackay, "Tracking the distribution of persistent organic pollutants," Environmental Science and Technology, vol. 30, no. 9, pp. 390-396, 1996.

[6] H. Hung, P. Blanchard, C. J. Halsall et al., "Temporal and spatial variabilities of atmospheric polychlorinated biphenyls (PCBs), organochlorine (OC) pesticides and polycyclic aromatic hydrocarbons (PAHs) in the Canadian Arctic: results from a decade of monitoring," Science of the Total Environment, vol. 342, no. 1-3, pp. 119-144, 2005.

[7] K. S. B. Miglioranza, J. E. A. de Moreno, and V. J. Moreno, "Trends in soil science: organochlorine pesticides in Argentinean soils," Journal of Soils and Sediments, vol. 3, no. 4, pp. 264-265, 2003.

[8] N. Xue, X. Xu, and Z. Jin, "Screening 31 endocrine-disrupting pesticides in water and surface sediment samples from Beijing Guanting reservoir," Chemosphere, vol. 61, no. 11, pp. 15941606, 2005.

[9] Y. Z. Sun, X. T. Wang, and X. B. Xu, "Persistent organochlorine pesticide residues in fish from Guanting Reservoir, People's Republic of China," Bulletin of Environmental Contamination and Toxicology, vol. 74, no. 3, pp. 537-544, 2005.

[10] N. Xue, D. Zhang, and X. Xu, "Organochlorinated pesticide multiresidues in surface sediments from Beijing Guanting reservoir," Water Research, vol. 40, no. 2, pp. 183-194, 2006.

[11] H. Zhang, Y. Lu, R. W. Dawson, Y. Shi, and T. Wang, "Classification and ordination of DDT and $\mathrm{HCH}$ in soil samples from the Guanting reservoir, China," Chemosphere, vol. 60, no. 6, pp. 762-769, 2005.

[12] T. Y. Wang, Y. L. Lu, R. W. Dawson, Y. J. Shi, H. Zhang, and Y. Xing, "Effects of environmental factors on organochlorine pesticide residues in soils of the Guanting reservoir area, China," Journal of Environmental Science and Health B, vol. 41, no. 3, pp. 309-321, 2006.

[13] W. Luo, Y. L. Lu, J. P. Giesy et al., "Effects of land use on concentrations of metals in surface soils and ecological risk around Guanting reservoir, China," Environmental Geochemistry and Health, vol. 29, no. 6, pp. 459-471, 2007.

[14] T. Y. Wang, C. L. Chen, J. E. Naile, J. S. Khim, J. P. Giesy, and Y. L. Lu, "Perfluorinated compounds in water, sediment and soil from Guanting reservoir, China," Bulletin of Environmental Contamination and Toxicology, vol. 87, no. 1, pp. 74-79, 2011.

[15] W. Tieyu, L. Yonglong, S. Yajuan, and Z. Hong, "Spatial distribution of organochlorine pesticide residues in soils surrounding Guanting reservoir, People's Republic of China," Bulletin of Environmental Contamination and Toxicology, vol. 74, no. 4, pp. 623-630, 2005.

[16] T. Y. Wang, Y. L. Lu, Y. J. Shi, J. P. Giesy, and W. Luo, "Organochlorine pesticides in soils around Guanting reservoir, China," Environmental Geochemistry and Health, vol. 29, no. 6, pp. 491-501, 2007.

[17] J. H. Kim and A. Smith, "Distribution of organochlorine pesticides in soils from South Korea," Chemosphere, vol. 43, no. 2, pp. 137-140, 2001.

[18] W. Y. Hu, Y. L. Lu, G. Wang et al., "Organochlorine pesticides in soils around watersheds of Beijing reservoirs: a case study in guanting and Miyun reservoirs," Bulletin of Environmental Contamination and Toxicology, vol. 82, no. 6, pp. 694-700, 2009.

[19] W. Y. Hu, Y. L. Lu, T. Y. Wang et al., "Spatial variability and temporal trends of $\mathrm{HCH}$ and DDT in soils around Beijing
Guanting reservoir, China," Environmental Geochemistry and Health, vol. 32, no. 5, pp. 441-449, 2010.

[20] A. Aguilar, "Relationship of DDE/SIGMA DDT in marine mammals to the chronology of DDT input into the ecosystem," Canadian Journal of Fisheries and Aquatic Sciences, vol. 41, no. 6, pp. 840-844, 1984.

[21] X. Qiu, T. Zhu, B. Yao, J. Hu, and S. Hu, "Contribution of dicofol to the current DDT pollution in China," Environmental Science and Technology, vol. 39, no. 12, pp. 4385-4390, 2005.

[22] NMH, "The Netherlands ministry of housing, spatial planning and environment's circular on target values and intervention values for soil remediation," 2000, http://www.esdat.net/ Environmental\%20Standards/Dutch/annexS_I2000Dutch\%20 Environmental\%20Standards.pdf.

[23] W. Luo, T. Y. Wang, Y. L. Lu et al., "Landscape ecology of the Guanting reservoir, Beijing, China: multivariate and geostatistical analyses of metals in soils," Environmental Pollution, vol. 146, no. 2, pp. 567-576, 2007.

[24] S. Yajuan, L. Yonglong, Z. Hong, W. Tieyu, and X. Ying, "Persistent organic pollutants control strategy in China," Journal of Environmental Sciences, vol. 17, no. 2, pp. 309-314, 2005.

[25] H. Zhang, Y. Lu, Y. Shi, T. Wang, Y. Xing, and R. W. Dawson, "Legal framework related to persistent organic pollutants (POPs) management in China," Environmental Science and Policy, vol. 8, no. 2, pp. 153-160, 2005.

[26] M. H. Lau, K. M. Leung, S. W. Wong, H. Wang, and Z. G. Yan, "Environmental policy, legislation, and management of persistent organic pollutants (POPs) in China," Environmental Pollution, vol. 165, pp. 182-192, 2012. 


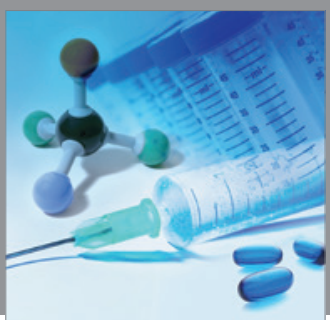

International Journal of

Medicinal Chemistry

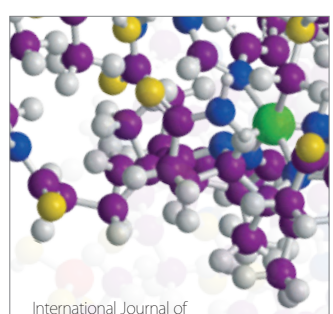

Carbohydrate Chemistry

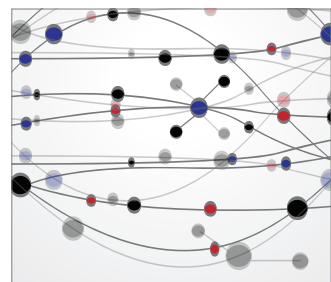

The Scientific World Journal
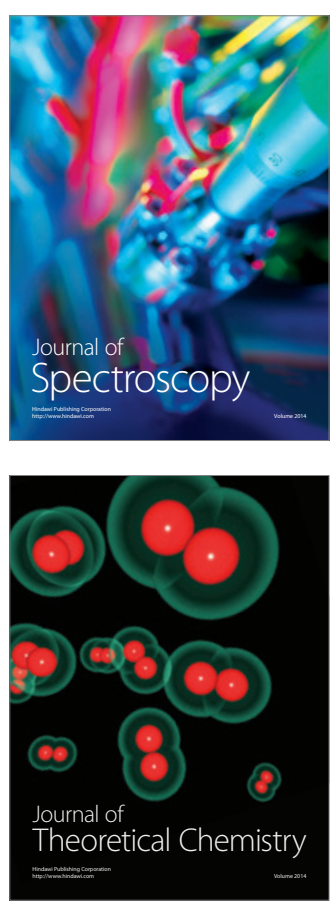
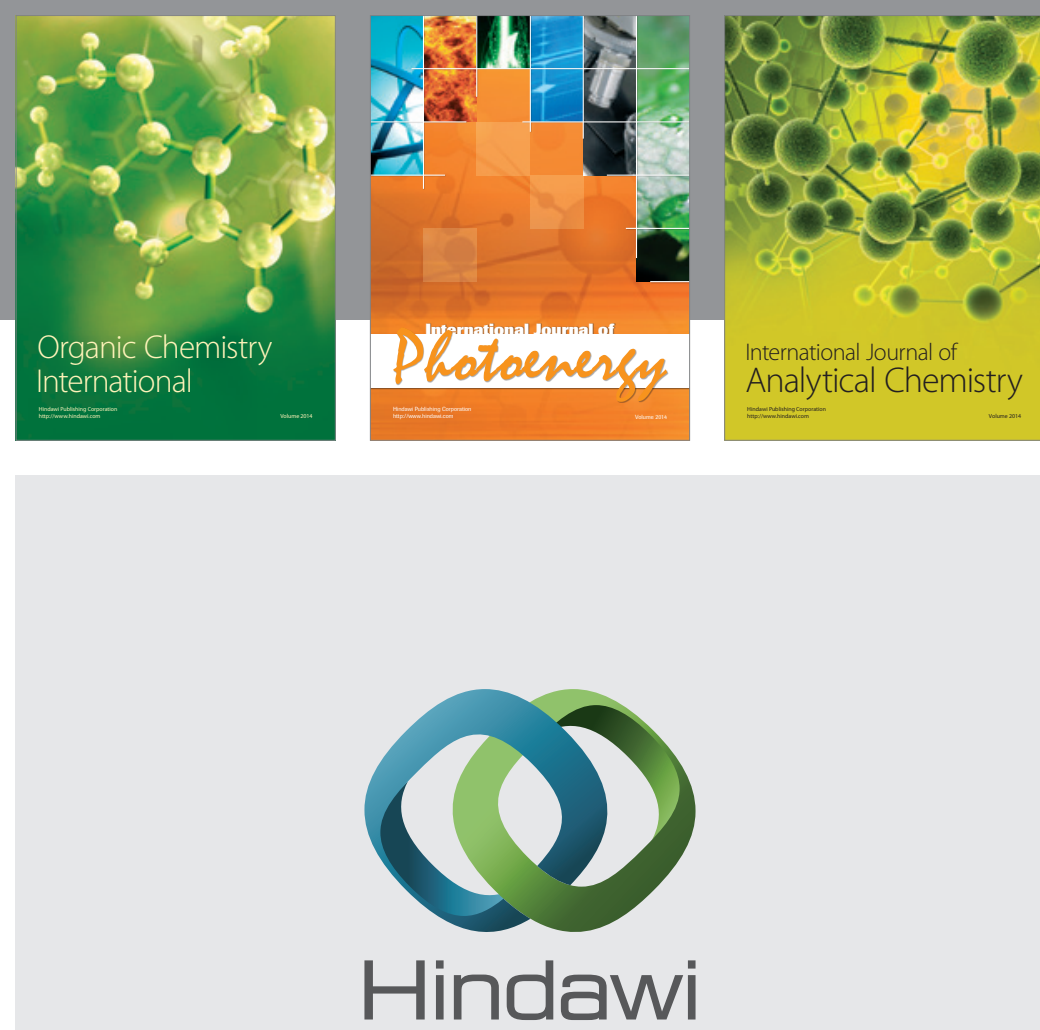

Submit your manuscripts at

http://www.hindawi.com
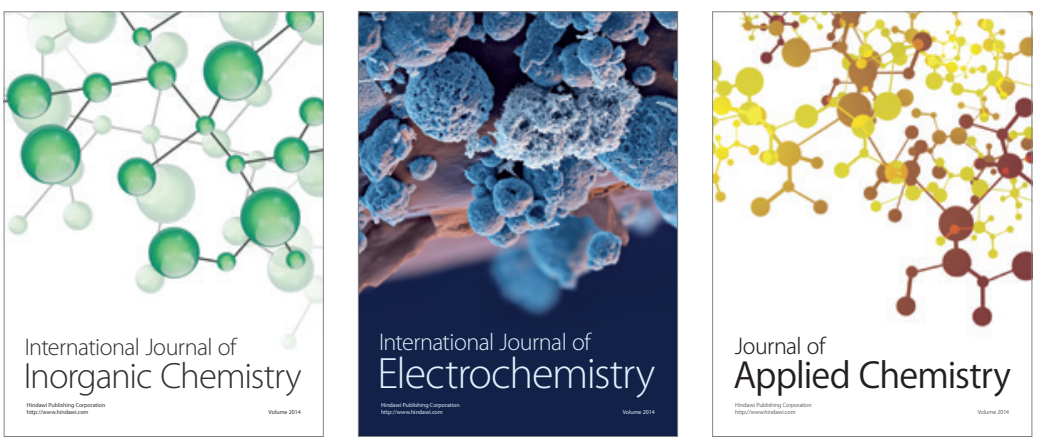

Journal of

Applied Chemistry
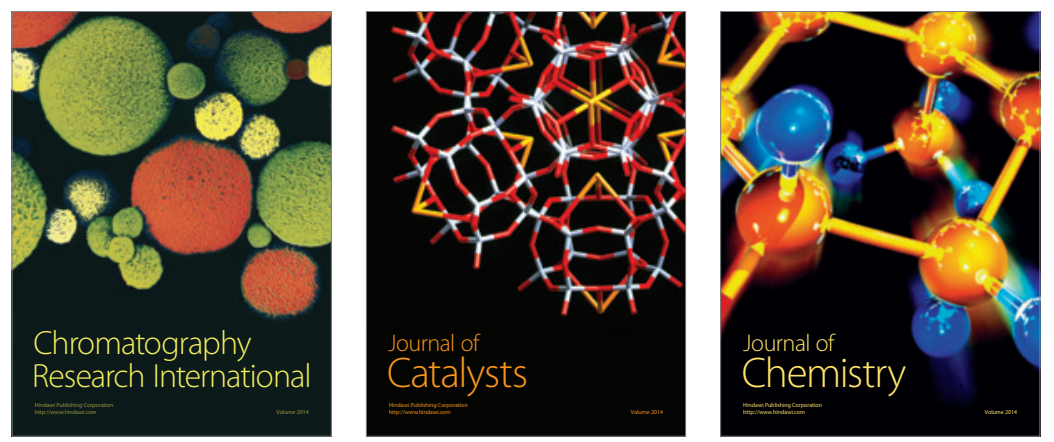
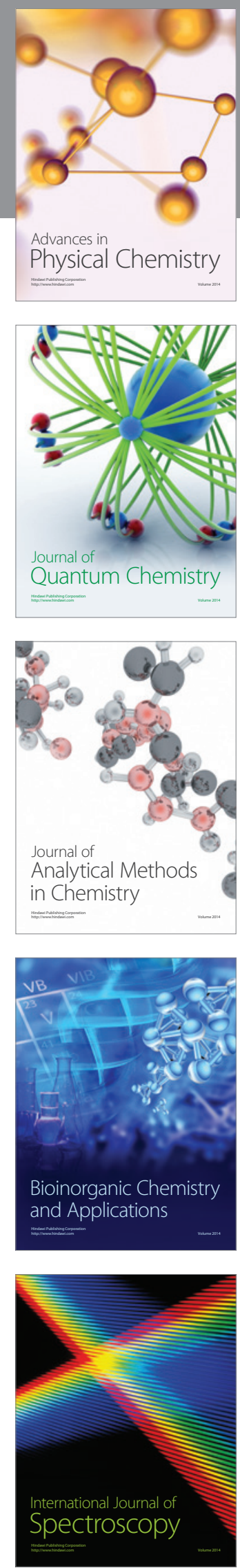